\title{
Study of menstrual disorder in adolescent girls at tertiary care centre in rural area
}

\author{
Anubhuti Yadav*, Deepa L. Masand \\ Department of Obstetrics and Gynecology, National Institute of Medical Sciences and Research, Jaipur, Rajasthan, \\ India
}

Received: 20 February 2018

Accepted: 27 March 2018

*Correspondence:

Dr. Anubhuti Yadav,

E-mail: dr.anubhuti1991@gmail.com

Copyright: (c) the author(s), publisher and licensee Medip Academy. This is an open-access article distributed under the terms of the Creative Commons Attribution Non-Commercial License, which permits unrestricted non-commercial use, distribution, and reproduction in any medium, provided the original work is properly cited.

\section{ABSTRACT}

Background: Total adolescent world population is $16 \%$. Adolescents (10-19 years) constitute $21.3 \%$ i.e. nearly $1 / 5^{\text {th }}$ of total population of India. $19 \%$ of the total population-faces a series of serious challenges not only affecting their growth and development but also their livelihood as adults. The objective of the current study was to observe the menstrual disorders among adolescent females and to observe the demographic profile and assess hygiene practices during menstruation and grade of anemia due to menstrual morbidity.

Methods: A random selection of adolescent's females were done from gynaecology outpatient department at a tertiary care hospital in rural area. Study done on 180 adolescent girls from January 01, 2016 to June $31^{\text {st }}$, 2017, it is a descriptive type of observational study. Counseling done of adolescent females on menstrual hygiene and nutrition. Results: Most common menstrual morbidity seen in this study is dysmenorrhea (41.66\%) followed by heavy menstrual bleeding i.e. $25 \%$ and irregular menstrual bleeding (13.33\%) subsequently. All these problems are associated with their practices used during menstruation. Poor menstrual hygiene was seen associated with 30 to $35 \%$ of abdominal cramps and mood swings, heavy menstrual bleeding and nutritional deficiency leads to moderate anemia (7 to10 gm\%) in $83 \%$.

Conclusions: Due to unhygienic practices and lack of education and awareness about hygiene many of the girls were suffering from reproductive tract infections and poor nutrition leads to anemia. So, we all need to educate them about hygiene and spread awareness about the various services provided by the government like supplying of sanitary napkins to overcome infections.

Keywords: Adolescents, Dysmenorrhea, Hygiene, Menstruation, Morbidity

\section{INTRODUCTION}

"Adolescents are the critical mass of asset which in future would be the biggest dividends to the country's economy; thereby their health and wellness are of utmost priority." Adolescence represents a window of opportunity to prepare for a healthy adult life.

Adolescence is the period of physical, psychological and social maturation from childhood to an adult. Total adolescent world population is $16 \%$. Adolescents (10-19 years) constitute $21.3 \%$ i.e. nearly $1 / 5$ th of total population of India. ${ }^{1} 19 \%$ of the total population-faces a series of serious challenges not only affecting their growth and development but also their livelihood as adults.

Yet adolescent females remain a largely neglected, difficult-to-measure, and hard-to-reach population, in which the needs of adolescent girls in particular are often ignored. ${ }^{2}$ "Ensuring the nutritional, health and educational needs of adolescent population, particularly 
girls, remains a key challenge for India." Puberty marks the early half of adolescence. Though it is a continuous process, for convenience sake, adolescence is generally divided into three phases: early (10-13 years), mid (14-16 years) and late (17-19 years) puberty. Puberty is a period during which secondary sex characters begin to develop and the capability of sexual reproduction is attained. ${ }^{3}$

The manner in which a girl learns about menstruation and its associated changes have an impact on her response to the event of menarche. Although menstruation is a natural process, it is linked with several misconceptions and practices, which sometimes result into adverse health outcomes. $^{4}$

The commonest problems in adolescent are heavy menstrual bleeding, irregular menstrual bleeding, dysmenorrhea, amenorrhea and pre-menstrual syndrome. Many times menstrual irregularities can be due to incomplete maturation of hypothalamic-pituitary-ovarian axis. This often leads to anxiety, depression and other such psychological problems among the adolescents. The sexual exposure during adolescence is concern with the risk of sexuality transmitted infections such as HIV infection, teenage pregnancy.

Many adolescents with menstrual disturbances never present to their family doctor or gynecologist. The American college of obstetrics and gynecologist (ACOG).

Take a proactive stance in adolescent health by recommending an initial visit to a gynecologist for health guidance, screening and the provision of preventative services around the age of $13-15$ years. ${ }^{5}$

Gynecologic problems of adolescents occupy a special space in the spectrum of gynecologic disorders of all ages. Menstrual disorders affect $75 \%$ of females. The first menstruation (menarche) occurs between 11 and 15 years with a mean of 13 years.

Knowledge of the length and variation of the menstrual cycle is necessary for patient education for identifying deviation from normal to guide clinical evaluation. These disorders are often the source of anxiety for female adolescents and their family at large. ${ }^{6}$

The objectives of the present study are:

- To study menstrual disorders among adolescent females attending gynecology outpatient department at a tertiary care hospital in rural area.

- To observe the demographic profile of study participants and to assess hygiene practices followed during menstruation.

- To evaluate the grade of anemia in study participants due to menstrual morbidity and suggest suitable recommendation based on findings.

\section{METHODS}

\section{Place of Study}

Department of Obstetrics and Gynecology, National, Institute of Medical Science and Research, Jaipur. It was a descriptive type of observational study. Study period was from January $01^{\text {st }} 2016$ to June $31^{\text {st }} 2017$.

\section{Sample Size}

180 adolescent girls were taken who attended out patient. The sample size for this study was calculated by using the following formula:

$\mathrm{N}=4 \mathrm{p} \mathrm{q} / \mathrm{L}^{2}$

\section{Inclusion criteria}

- Girls who were between the age group of 10-19 years with any complaints of menstrual disorder and Adolescent girls who attended adolescent clinic.

\section{Exclusion criteria}

- The girls who were suffering from any chronic condition e.g. T.B. and all adolescent girls with normal menstrual cycles.

\section{Methodology}

The adolescent girls of age group between 10-19 years who visited the Department of Obstetrics and Gynecology outpatient with the complaints of menstruation were selected for the study.

The relevant parameters were recorded in a pre-structured questionnaire which includes identification data, demographic characteristics, socioeconomic data, menstrual history and menstrual hygiene history. In this study randomly 180 adolescent girls were taken after applying inclusion and exclusion criteria.

A detailed history of menstrual problems, and in addition to this general examination height, weight and a predesigned questionnaire was filled for socio-demographic profile and menstrual hygiene.

\section{RESULTS}

Table 1 that maximum number of adolescent girls i.e $42.78 \%$ belong to $10-13$ years of age which are in maximum number with menstrual morbidities and $36.11 \%$ and $21.11 \%$ belong to $14-16$ years and $17-19$ years respectively.

The important information about hygiene practice during menstruation was tabulated in Table 2 and it tells us that absorbent used during flow is old cloth by $66 \%$ of girls 
and homemade pads are used by $27 \%$ and only $5 \%$ girls can afford sanitary towels.

Table 1: Age wise distribution.

\begin{tabular}{|lll}
\hline Age (Years) & No & $\%$ \\
\hline $10-13$ & 77 & 42.78 \\
\hline $14-16$ & 65 & 36.11 \\
\hline $17-19$ & 38 & 21.11 \\
\hline Total & 180 & 100.00 \\
\hline
\end{tabular}

Frequency of changing pad is $33 \%$ when it comes to number 4 or more per day and $44 \%$ changes pad once or twice in 24 hours. The girls who are using reutiliazable cloths are cleaning it only water $(60 \%)$ and or water with soap (40\%).

The washed cloth is dried under sunlight by only $30 \%$ of these and majority of girls $(70 \%)$ are drying it without sunlight. $48 \%$ of these girls are reusing the same cloth for 3 or cycles only $20 \%$ girls are disposing after single use. $60 \%$ of adolescent girls have not told about cleaning of their perineum during menstrual cycle.

The relation of heavy menstrual bleed and anemia is depicted in Table 3 and it is seen that girls with less than $7 \mathrm{gm} \%$ hemoglobin, 50\% of them are having HMB and 129 girls who were having 7-10 gm \% $\mathrm{Hb}$ about $82.22 \%$ showed HMB. Since there is no scoring system to designate an adolescent's girl as hygienic or unhygienic, we have taken participants who are using cloth and reusing it as unhygienic participants. This table showing that $48 \%$ literate and $52 \%$ illiterate of adolescent girls are having unhygienic practices during menstruation, where as $90 \%$ literate and $10 \%$ illiterate adolescent's girls are having hygienic practices.

Table 2: practice of menstrual hygiene.

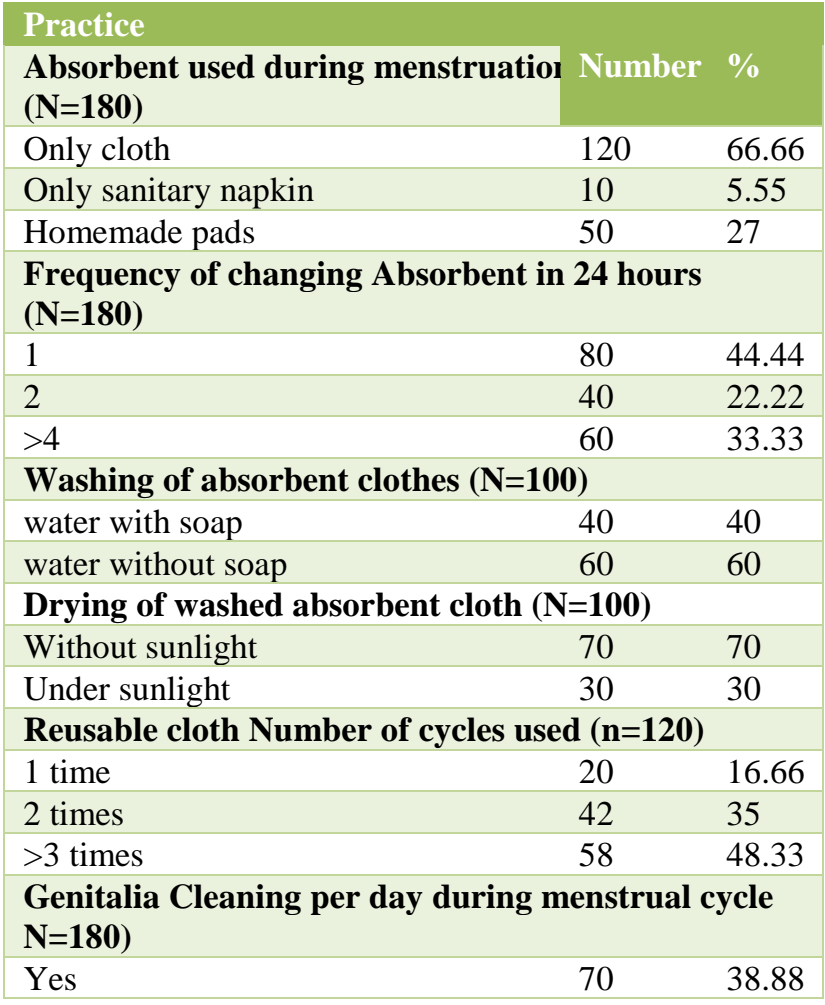

Table 3: Relation of heavy menstrual bleeding with anemia.

\begin{tabular}{|c|c|c|c|c|c|c|}
\hline \multirow[t]{3}{*}{ Hemoglobin (gm/dl) } & \multicolumn{4}{|c|}{ Heavy Menstrual Bleeding } & \multirow{2}{*}{\multicolumn{2}{|c|}{ Total }} \\
\hline & \multicolumn{2}{|c|}{ Present } & \multicolumn{2}{|c|}{ Absent } & & \\
\hline & No. & $\%$ & No. & $\%$ & No. & $\%$ \\
\hline$<7$ & 3 & 6.66 & 3 & 2.22 & 6 & 50 \\
\hline $7-10$ & 37 & 82.22 & 92 & 68.14 & 129 & 28.68 \\
\hline $11-12$ & 5 & 11.11 & 35 & 25.92 & 40 & 12.50 \\
\hline$>12$ & 0 & 0 & 5 & 3.70 & 5 & 0 \\
\hline Total & 45 & 100 & 135 & 100 & 180 & 100.00 \\
\hline
\end{tabular}

Table 4: Relation between menstrual hygiene practices and education status

\begin{tabular}{|lllllll|}
\hline \multirow{2}{*}{ Education status } & \multicolumn{2}{l}{$\begin{array}{l}\text { Menstrual hygiene } \\
\text { Unhygienic }\end{array}$} & & Hygiene & & Total \\
& No. & \% & No. & \% & No. & \% \\
\hline Literate & 48 & 48 & 72 & 90 & 120 & 100.00 \\
\hline Illiterate & 52 & 52 & 8 & 10 & 60 & 100.00 \\
\hline
\end{tabular}

\section{DISCUSSION}

Adolescence is the transition period of the human being where physical, emotional, psychological changes come in the body and psyche. Menarche is the important landmark of the adolescence which prepares a girl for the future motherhood. H-P-O axis take around 18 months to become mature. Adolescent girls have many problems 
regarding menstrual abnormalities and it was seen that they are shy to discuss their problems and to maintain proper hygiene during menstruation. In this study Dysmenorrhea is most commonly seen i.e. $41.66 \%$ it may be either primary or secondary. Primary dysmenorrhea occurs in the absence of any identifiable pathology and is attributed to the production of prostaglandins during the menstrual cycle.

Secondary dysmenorrhea occurs when there is an identifiable pelvic or hormonal pathology causing pain. The most common gynecologic causes of secondary dysmenorrhea are endometritis and pelvic inflammatory disease (PID). These conditions are associated to poor nutrition, poor menstrual hygiene practices and also lack of awareness ${ }^{7}$. A similar study done by Sharma $\mathrm{S}$ et al. had $53.5 \%$ girls with dysmenorrhea, whereas A Agarwal et al. noticed $37.96 \%$ of dysmenorrhea in their study. In the present study heavy menstrual bleeding $(25 \%)$ rate is higher as we performed this study in rural area and due to heavy menstrual bleeding moderate anemia is seen in $83 \%$ of adolescent females., 8 A similar study of Bandkhadke et al. had $30.8 \%$ of adolescents had menorrhagia and anemia was the leading cause of morbidity. ${ }^{10}$ Menstrual morbidities can be controlled by improving nutrition level of adolescent females, for this government of India had started a lot of programs like anganwadi's, mid-day meal so that adolescent girls will get better nutrition. Adolescents have increased nutritional requirements demanding diet rich in protein, vitamins, calcium, iodine, phosphorus and iron due to rapid growth spurt and increased physical activity. NFHS-3 data shows, in the age group 15-19 year, $47 \%$ girls thin, $56 \%$ girls were anemic.

In the present study 120 girls were using clothes and out of these 100 girls were reusing the cloth by washing and drying inside the house only 30 adolescent females were drying under sunlight according to the guidelines given by ministry of health and family welfare i.e cloth used during menstruation should be dried under sun and should be kept in clean bag during intermenstrual period.

A study done by Sharma S et al. $63.3 \%$ of the girls were using sanitary pads while cloth was used by $25.3 \%$ and cloth and pads both were used by $11.4 \%$ girls and $11.52 \%$ were reusing the cloth. ${ }^{7} 52 \%$ of illiterate adolescent females were using unhygienic practices during menstruation, while $10 \%$ of them were using hygienic practices as they were using sanitary napkins and disposing them properly. While $48 \%$ literate girls were using unhygienic practices as they were using same cloth pieces for next cycle.

And all this practice might be due to non-availability of sanitary latrine, in this study we have seen that only $33.33 \%$ were having sanitary latrine.

Due to lack of sanitary latrines young girls were not able to change frequently and not getting enough space for disposal and this leads to reproductive tract infections and that can lead to future problems like infertility. So, if we will treat the basic problem we can achieve a good and healthY population of adolescent females. Lack of knowledge and awareness about menstrual hygiene has attributed to various factors seen in this study.

The above findings reinforce the need to encourage safe and hygienic practices among the adolescent girls and bring them out of traditional beliefs, misconceptions and restrictions regarding menstruation. The investigators improved the general awareness about cause of menstruation and the organs involved. Use of sanitary napkins was promoted and various schemes regarding menstrual health were briefed to the students. Early awareness can prevent students from suffering from the various reproductive tract infections.

\section{CONCLUSION}

Adolescent girls presenting to gynecological out door patient department with various menstrual morbidities including Heavy menstrual bleeding, irregular menstrual bleeding, inter-menstrual bleeding and dysmenoorhea. We need to screen them and treat accordingly.

Due to unhygienic practices most probably because of poor nutrition level and lack of education and awareness about hygiene many of the girls were suffering from reproductive tract infections and anemia.

We need to educate them about hygiene and spread awareness about the various services provided by the government like supplying of sanitary napkins to overcome infections. Other programmes where in nutritional supplementations provided should be told to the general population to improve their health.

Funding: No funding sources

Conflict of interest: None declared

Ethical approval: The study was approved by the Institutional Ethics Committee

\section{REFERENCES}

1. Dambhare DG, Wagh SV, Dudhe JY. Age at menarche and menstrual cycle pattern among School Adolescent girls in central India. Global Journal of health science.2012;4:105-11.

2. Kotecha PV, Sangita Patel, R.K.Baxi, V.S.Mazumdar, Shobha mishra, Ekta Modi, Mansi Diwanji Reproductive health awareness among rural school going adolescents of Vadodara district 2009;3:94-9.

3. Ghai OP textbook of pediatrics, $8^{\text {th }}$ ed. 2013. Published by CBS publishers and distributers pvt ltd.

4. Shanbhag D, Shilpa R, D'Souza N, Josephine P, Singh J, Goud BR. Perception regarding menstruation and practices during menstrual cycles among high school going adolescent girls in resource 
limited settings around Bangalore city, Karnataka, India.2012;4:1353-62.

5. Martha hickey and Adam Balen. Menstrual disorders in adolescence: investigation and management.2003;9:493-504.

6. Joydeb Roychowdhury, Snehamay chaudhuri, Asim Sarkar, Pranab Kumar Biswas. A study to evaluate the etiological factors and management of pubery menoorhagia. 2008;7:5.

7. Dsalegn tegabu zegeye, berihun megabiaw and aba mulu. Age at menarche and menstrual pattern of secondary school adolescent in north west Ethopia. 2009;9:29.

8. Sharma S, Mehra D, Kohli C, Singh MM. Menstrual hygiene practices among adolescent girls in a resettlement colony of Delhi: a cross-sectional study.
Int J Reprod Contracept Obstet Gynecol. 2017; 6:1945-51.

9. Anil A, Anju A. A study of dysmenorrhea during menstruation in adolescent girls. Indian J Comm Medi: official publication of Indian Assoc Prevent and Social Medi. 2010;32:159.

10. Ganesh MB, Pankaj PS, Anand Nathu Bhalerao, Ramesh Anantrao Bhosale, Ajay Sahebrao Chandanwale Menstrual morbidities in adolescent female. 2015;2:2349-3178.

Cite this article as: Yadav A, Masand DL. F Study of menstrual disorder in adolescent girls at tertiary care centre in rural area. Int J Reprod Contracept Obstet Gynecol 2018;7:1979-83. 